\title{
THE WORKS ATTRIBUTED TO ISAAC OF ANTIOCH: A[NOTHER] PRELIMINARY CHECKLIST
}

\author{
EDWARD G. MATHEWS, JR. \\ 204 HigHFIELD DR. \\ TUNKHANNOCK, PA 18657
}

\begin{abstract}
Isaac of Antioch is lauded by several of his contemporaries as one of the most prolific of all early Syriac authors. Despite these accolades, the works attributed to him remain for all intents and purposes entirely unedited. Less than a third of the works known to be attributed to him exist in any printed form. This list, the fourth such, is the latest and most complete - albeit still provisional — attempt to record the incipits of this vast corpus.
\end{abstract}

Although one still occasionally finds an apologia that Ephrem has not been given his due in Western circles, the fact is that the fourth-century Syrian deacon has been the object of much study in recent decades-among both eastern and western scholars - and so has finally attained his proper place in contemporary scholarship -though this is not at all to say that the last word has been said! Not only have all of his genuine Syriac works been edited, mostly by Dom Edmund Beck, but there has also been recent advancement on the non-Syrian works attributed to him. Many of these texts have now been translated into modern western languages, 
although on this front there still remains work to be done. In addition to critically edited texts, there has been a remarkable amount of secondary study, both scholarly and popular, not only by such scholars as Beck, Leloir, Brock, Murray, etc., but by a rapidly growing number of other scholars. ${ }^{1}$ Alas, this felicitous situation does not exist for a number of Ephrem's near contemporaries and literary successors. Even within the field of Syriac studies itself too many other Syriac writers remain relatively ignored.

Some fifteen years ago Sebastian Brock noted, with great dismay, "the underdeveloped state of Syriac studies,"2 with particular regard to three of the most prolific writers of the fifth and sixth centuries: Isaac of Antioch, Jacob of Sarug, and Narsai, whose collective works span the christological divide of this period. At that time, Brock encouraged "scholars to turn their attention to this fruitful field of study." ${ }^{3}$ Nevertheless, while some minimal progress has been made with the latter two authors, nearly none has been made with the corpus that goes under the name of Isaac of Antioch. In a previous article in this journal, I compiled a short bibliography of the editions, translations, and secondary literature concerned with this corpus. ${ }^{4}$ While this article was intended as a sort of preliminary vade mecum, it also served to highlight the dearth of serious work on this corpus.

In a footnote to this same article, I made allusion to a second preliminary reference tool that was in the course of preparation. I have been compiling, on and off for several years, a comprehensive catalogue of the manuscript works attributed to Isaac. In its fin-

${ }^{1}$ For all these facets of Ephrem studies, the very useful articles J. Melki, "Saint Ephrem le Syrien, un bilan de l'édition critique" (ParOr 11 [1983]), 3-88, and S.P. Brock, "A Brief Guide to the Main Editions and Translations of the Works of St. Ephrem" (The Harp 3 [1990]), 7-29, have now been superseded by K. den Biesen, Bibliography of Ephrem the Syrian (Published by author, 2002).

2 S.P. Brock, "The Published Verse Homilies of Isaac of Antioch, Jacob of Serugh, and Narsai: Index of Incipits” (JSS 32 [1987]), 279-280, reiterated in S.P. Brock, "Syriac Studies in the Last Three Decades: Some Reflections," in VI Symposium Syriacum 1992, Orientalia Christiana Analecta 247, ed. R. Lavenant (Rome: Pontificio Istituto Orientale, 1994), 28, and echoed by A. de Halleux, "Vingt ans d'étude critique des églises syriaques," in The Christian East: Its Institutions and its Thought. A Critical Reflection, Orientalia Christiana Analecta 251, ed. R.F. Taft (Rome: Pontificio Istituto Orientale, 1996), 155.

${ }^{3}$ S.P. Brock, "The Published Verse Homilies," 279.

4 E.G. Mathews, Jr., "A Bibliographical Clavis to the Corpus of Works attributed to Isaac of Antioch" (Hugoye 5.1 [2002]). 
ished form, it will be published by the Middle Eastern Texts Initiative in the Subsidia volumes of its Eastern Christian Texts Series. It is hoped that this catalogue will provide a listing of every known work attributed to Isaac, by title and incipit, together with all the known manuscripts, with the relevant folio numbers, in which that particular work can be found. I hope also to include a second listing, an itemized list of all those manuscripts that contain only or primarily works of Isaac. These two lists will be prefaced by a preliminary study of the manuscript tradition. Other scholars and friends, associated with both METI and Hugoye, thought that it might be a good idea to publish here a preliminary checklist of incipits while the full catalogue is in preparation. ${ }^{5}$

There already exist three such catalogues or checklists of the works attributed to Isaac. The first published list was part of Joseph Assemani's great catalogue of Syrian authors and their works (see reference, below). In this initial catalogue, culled almost exclusively from the collection of Syriac manuscripts in the Vatican Library, Assemani listed 105 mêmrê, each with a brief description of its contents, under the heading of Isaac of Antioch. A little more than a century and a half later Gustav Bickell, in the introduction to his partial edition of Isaac's works (see reference, below), compiled a second, fuller list of incipits of works attributed to Isaac. Bickell compiled this list from his research in most of the larger western collections of Syriac manuscripts. Thus, Bickell was able to expand the list that Assemani had compiled to a total of 182 works whose incipits are known, along with another nine fragments that survive without incipit. Finally, in the article already cited above, Sebastian Brock provided a third checklist of incipits of the works attributed to Isaac. Brock's list, limited to mêmrê only, was culled almost exclusively from those texts edited by Bickell and Bedjan (see reference, below), and from the previous lists of Assemani and Bickell.

The checklist of incipits of Isaac's works which I present here includes a total of 185 mêmrê and 19 madräšê. While it contains much of the same information as found in these previous lists, this new checklist has the slight improvement over the two more recent lists of Bickell and Brock in that it provides more known works, fuller incipits in most cases, as well as a more comprehensive list of titles, though some still remain unknown. Working on the great foundation laid by these previous scholars, I was also able tacitly to

5 Among all these persons, I would like here to record very special thanks to Mr. Kristian Heal who has, in addition to his constant encouragement on this and other projects, graciously made available to me a number of texts to which I would not otherwise have had access. 
fix a few inadvertent typographical errors that had crept into their work. It is hoped, therefore, that this list will be of some use to scholars of Syriac literature, not only for its own sake but also as a first step, in response to Sebastian Brock's call decades ago, toward reparating a great lacuna in Syriac studies. This list in no way purports to make any attempt at sorting out the thorny problem of how many Isaacs - or other authors - there are whose works are included in this collection. For now, I have simply listed all the works attributed to Isaac, including those sharing attribution with Ephrem. I have included some works listed by Bickell that are only fragmentary and likely constitute parts of other known works. I have also refrained from listing every variant found in the incipit verses. It is more than probable that there exist not a few other works that can be attributed to Isaac, but which have no such manuscript attribution. ${ }^{6}$ Only good critical editions and long, careful study can help to sort out these problems.

As with my previous "Bibliographical Clavis", the electronic medium afforded by Hugoye provides me with the opportunity to solicit assistance from fellow scholars with regard either to additional works attributed to Isaac or with additional manuscript entries from libraries to which I do not have access. I believe that I have scoured the major western catalogues and, in some cases, I was able to examine the manuscripts in situ. As every Syriac scholar knows, the state of the eastern collections, while improving, is not always what one might desire. Coupled with this is the fact that life, with its own unforeseen "twists and turns" has left me unable to check the eastern collections with the same care as I hope I have done with the western collections-hence my subtitle, "A[nother] Preliminary Checklist". Therefore, it would be of great help to me if anyone who had access to such collections would be so kind as to relay any information on such works attributed to Isaac of Antioch or on works whose incipits are found in this list but are attributed to others, such as Ephrem or even, as occurs on occasion, Isaac of Nineveh. Such assistance will be acknowledged with extreme gratefulness in the final product.

For ease of reference, I have utilized the following sigla in conjunction with my checklist. In brackets, below the titles, I have made comprehensive cross-references to all three of the previous

${ }^{6}$ In addition to works that share attribution with Ephrem in the manuscript tradition, it is likely that some works attributed only to Ephrem actually belong to Isaac. I am currently preparing editions of several such mêmrê but, for the purpose of this checklist, I have not presumed the conclusions of this work. 
checklists of Isaac's works. In the case of each of these, the reference number is to the item number of each checklist, not to a page number. Where a particular work has already been edited, I have also given precise references, with pagination, to the editions of Bedjan and Bickell. In the case of Bedjan's edition, I have provided the page numbers, whereas in the case of Bickell, a lonely Arabic number following the abbreviation indicates the number in his list found in vol. I, pp. iv-viii, of his edition. When he has also edited that particular work, I have marked it by a colon after that Arabic numeral, followed by the volume and page numbers. All of these cross-references are found within brackets found in the line immediately below the title of the work.

A - J.S. Assemanus, Bibliotheca Orientalis Clementino-Vaticana I (Rome 1719) 207-234.

Be - P. Bedjan, ed., Homiliae S. Isaaci Syri Antiocheni I (Paris 1903).

$\mathrm{Bk}$ - G. Bickell, ed., Sancti Isaaci Antiochi Doctoris syrorum opera omnia, syriace, arabiceque primus edidit, latine vertit I-II (Gissae 1873-1877).

$\mathrm{Br}$ - S.P. Brock, "The Published Verse Homilies of Isaac of Antioch, Jacob of Serugh, and Narsai: Index of Incipits," JSS 32 (1987), 279-313.

L - T.J. Lamy, ed., Sancti Ephraem Syri Hymni et Sermones I-IV (Mechlinia 1882-1902).

\section{MÊMRÊ}

1. no title

[Bk 1; Br 3]

Inc.

Ritix Resy Rar

2. On Silence

Inc.



3. On [Deceased] Youths IV

[A 103; Bk 2; Br 4]

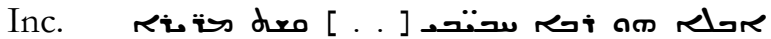


4. An Admonition

[A 48; Be 180-213; Bk 3; Br 5]

Inc.

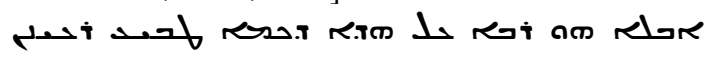

5. On Adam and Eve

[A 75; Bk 169; Br 8]

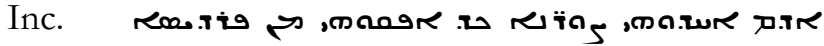

6. On Almsgiving

[A 51; Be 651-655; Bk 5; Br 10]

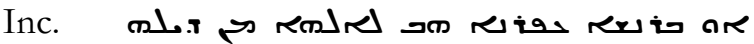

7. On the Incarnation of Our Lord

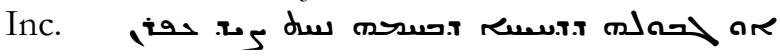

8. no title

[Bk 6; Br 14]

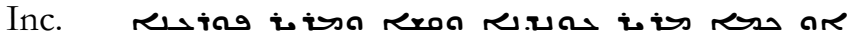

9. On the Rich Man and Lazarus

[A 23; Be 112-127; Bk 9; Br 16]

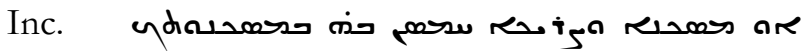

10. On that Bird who cried out the Trisagion in Antioch

[Be 737-788; Bk 7:I.84-174; Br 18]

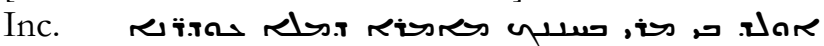

11. On Silence

[Bk 10; Br 24]

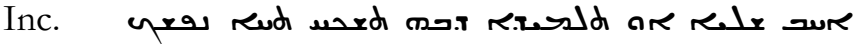

12. no title

[Bk 11; Br 25]



13. On the vigil of Monks

[L IV, 207-215]

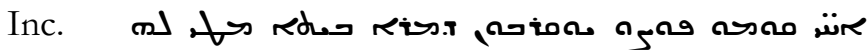


14. no title

[Bk 12; Br 27]

Inc.

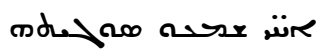

15. On the Crucifixion IV

[A 67 quart; Bk 170; Br 29]

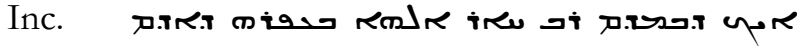

16. An Exhortation to Humility

[A 6; Be 329-350; Bk 13:II.162-202; Br 31]

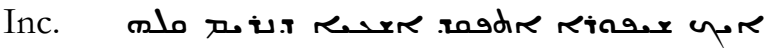

17. On the Crucifixion $V$

[A 67 quint; Bk 171; Br 35]

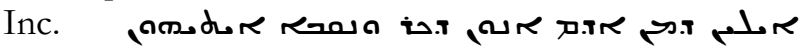

18. On Tyranny and Oppression III

[A 63 ter; Bk 15; Br 36]

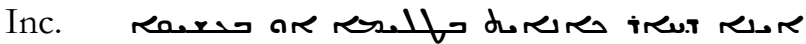

19. no title

[Bk 179; Br 37]

Inc. am Ragarer

20. An Admonition against Blasphemers

[A 12; Be 381-386; Bk 16; Br 39]

Inc.

21. Against those who go to Soothsayers

[Be 821-830; Bk 17:II.204-220; Br 40]

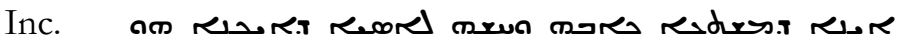

22. On Perfection

[Bk 101b; Br 41]

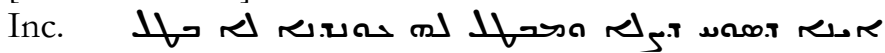

23. On Humility

[A 85; Bk 18; Br 42]

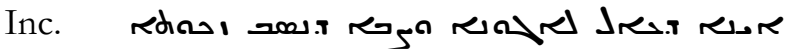


24. no title

[Bk 19; Br 43]

Inc. ram $x^{2} \cdot x^{2}$

25. On Solitaries, Mourners, and Hermits

[A 15; Be 49-70; L IV, 147-185; Bk 20; Br 45]

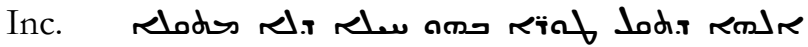

26. On Solitaries and Monks

[A 21; Be 81-106; Bk 21; Br 46]

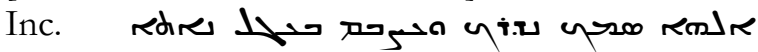

27. On Avarice

[A 3; Be 36-44; L IV, 225-239; Bk 22; Br 47]

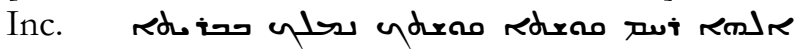

28. On the Humility of the Brethren

[A 4; Be 13-24; L IV, 241-261; Bk 23; Br 51]

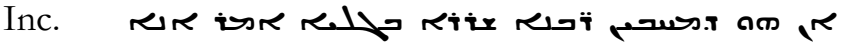

29. On Tyranny and Oppression I

[A 63 prim; Bk 24; Br 52]

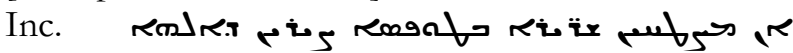

30. On the Censure of Conscience

[A 35; Be 566-576; Bk 25; Br 53]

Inc. idudu

31. On Repentance

[A 17; Be 76-80; Bk 26; Br 62]

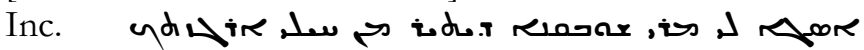

32. On the Sinful Woman

[A 93; Bk 27; Br 66]

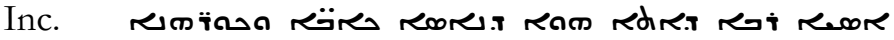

33. On Sitting in Silence and the Way of Righteousness

Inc. 
34. no title

[Bk 28]

Inc.

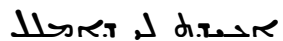

35. On Our Lord and On Faith

[Be 805-815; Bk 180:I.32-48; Br 70]

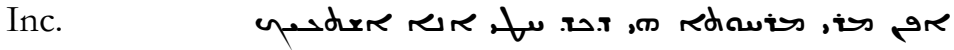

36. On Perfection

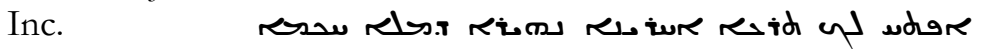

37. On the Crucifixion I

[A 67 prim; Bk 172; Br 78]

Inc.

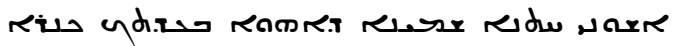

38. An Admonition to Monks

[A 104; Bk 30; Br 83]

Inc.

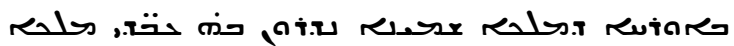

39. On the Ball that Children Use

[Bk 31; Br 85]



40. On Supplication

[A 62; Bk 32; Br 87]

Inc.

כרות

41. On Cain and Abel

[A 76; Bk 33; Br 88]

Inc.

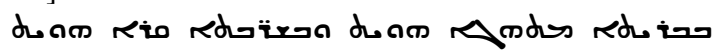

42. On Faith

[Bk 181:I.176-178; Br 91]

Inc.

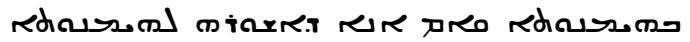

43. On Solitaries

[Bk 34; Br 93]

Inc.

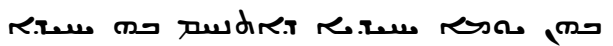


44. An Admonition on Falsehood

[A 13; Be 387-391; Bk 35; Br 95]

Inc.

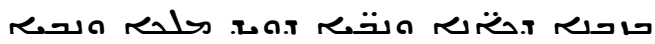

45. On Supplication

[A 36; Be 576-587; Bk 36; Br 96]

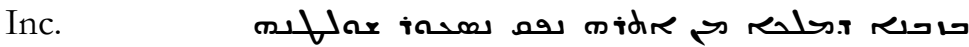

46. On the Enclosed Brethren VI

[A 26 sextus; Be 513-520; Bk 37; Br 97]

Inc.

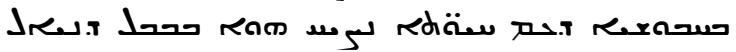

47. On All the Deceased II

[A 101; Bk 39; Br 107]

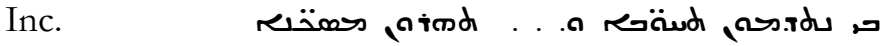

48. On Deceased Adolescents

[A 98; Bk 40; Br 117]

Inc.

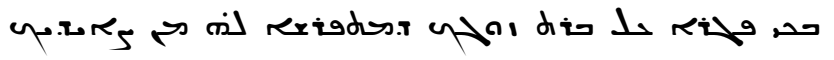

49. On the Nativity of Our Lord

[Bk 41; Br 120]

Inc.

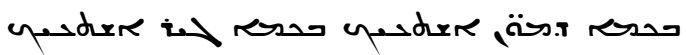

50. On Ezekiel's Chariot

[Bk 185:I.52]

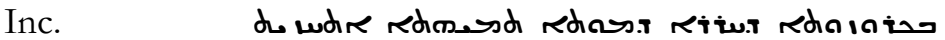

51. On the Ascension of Our Lord

[Bk 42; Br 121]

Inc.

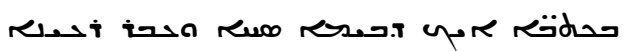

52. On Faith

[A 53; Be 655-664; Bk 43; Br 123]

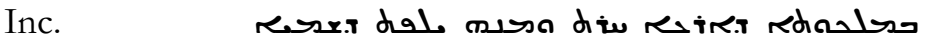

53. no title

[Bk 44; Br 132]

Inc.

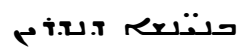


54. On the Coming of the Lord

[Bk 45; Br 134]

Inc.

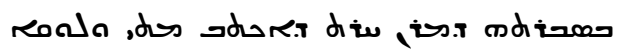

55. On the Saying of the Prophet Isaiah, "All flesh is grass"

[A 19; Be 408-420; L II, 313-333; Bk 46; Br 135]

Inc.

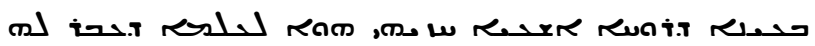

56. no title

[Bk 47]

Inc.

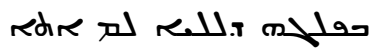

57. An Admonition

[A 49; Be 213-239; Bk 48; Br 136]

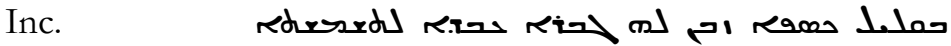

58. On the Perfection of the Brethren

[A 2; Be 296-305; Bk 49; Br 137; Zingerle']

Inc.

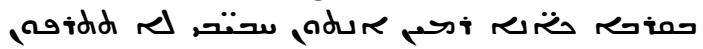

59. On the Nativity

Inc.



60. On the End of the World

[A 16; Be 71-75; Bk 50; Br 168]

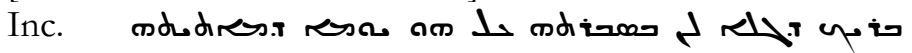

61. no title

[Bk 51; Br 169]

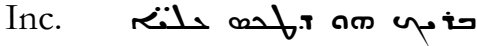

\section{A Lament}

[Bk 52; Br 171]

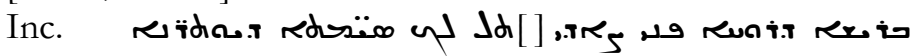

63. On the Samaritan Woman I

[A 79 prim; Bk 54; Br 181]

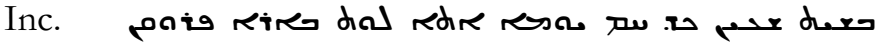

${ }^{7}$ P. Zingerle, Chrestomathia Syriaca (Rome 1871), 302-306. 
64. On the Enclosed Brethren III

[A 26 tert; Be 484-492; Bk 55; Br 182]

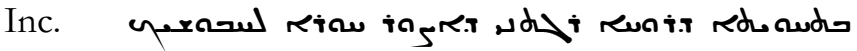

65. On Faith and the Incarnation

[Be 789-800; Bk I 2-24; Bk 56; Br 183]

Inc.

66. On the Lenten Fast I

[A 45 prim; Be 158-170; Bk 57:I.250-274; Br 188]

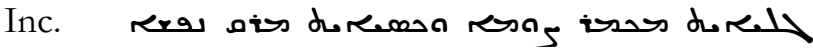

67. On the Verse, "It is good to confess the Lord"

[A 91; Be 815-821; Bk 58:I.294-306; Br 189]

Inc.

68. On Sacrifice

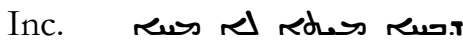

69. On the Plague in the Time of King David

[Bk 59; Br 193]

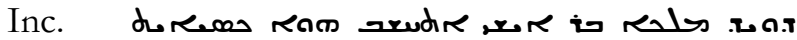

70. On the Enclosed Brethren VIII

[A 26 oct; Be 531-539; Bk 60; Br 197]

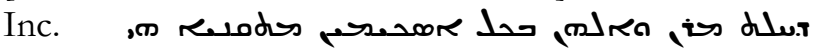

71. Against the Jews

[A 73; Bk 61; Br 199; $\mathrm{Kazan}^{8}$ ]

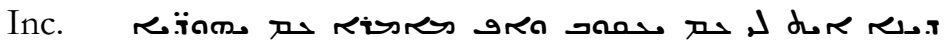

72. On the Prodigal Son II

[A 86 sec; Bk 63; Br 201]

Inc.

8 S. Kazan, "Isaac of Antioch's Homily against the Jews" (OrChr 45 [1961]), 30-53. 
73. On the Changes in the World and in the Mind

[A 50; Be 642-651; Bk 64; Br 204]

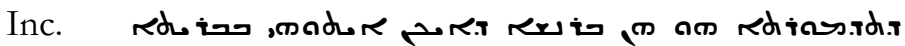

74. no title

[Bk 65]

Inc. Rim

75. no title

[Bk 66]

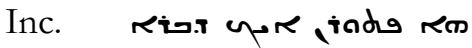

76. no title

[Bk 67]

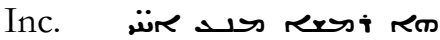

77. On Those Who Come for Instruction

[A 74; Bk 68; Br 206]

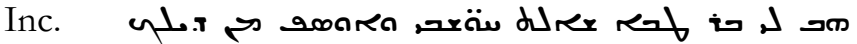

78. On Repentance

[L IV, 453-461; Bk 69; Br 207]

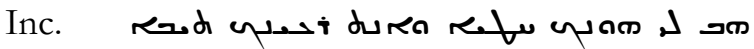

79. On the Martyrs Sergius and Bacchus

[Bk 182]

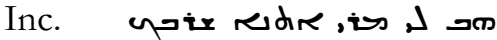

80. On the Faith

[A 9; Be 712-725; Bk 70:I.54-78; Br 216]

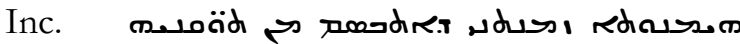

81. On the Crucifixion II

[A 67 sec; Bk 173; Br 217]

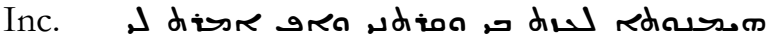

82. An Admonition

[A 20; Be 421-453; Bk 72; Br 219]

Inc. דidso 
83. no title

[Bk 73; Br 222]

Inc.

84. An Encouragement to Give Alms

[A 5; Be 305-328; Bk 74; Br 223]

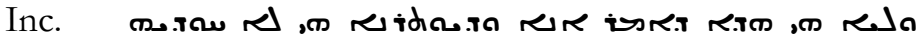

85. On Supplication I

[A 55 prim; Be 271-283; Bk 75; Br 225]

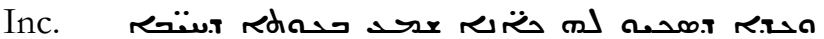

86. On Repentance

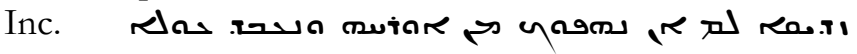

87. An Exhortation to Admonition

[A 22; Be 106-112; Bk 77; Br 233]

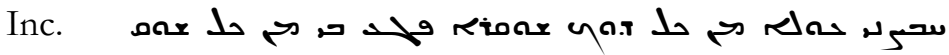

88. On the Faith and Against Nestorius and Eutyches

[Be 800-804; Bk 183:I.24-32; Br 234]

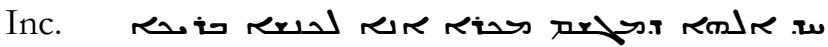

89. no title

[Bk 79]

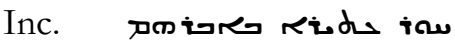

90. On the Prodigal Son I

[A 86 prim; Bk 78; Br 239]

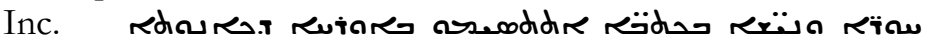

91. On Deceased Priests

[A 95; Bk 80; Br 240]

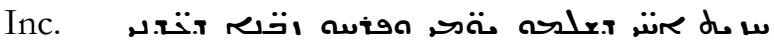

92. On the Deceased

[A 84; Bk 174; Br 245]

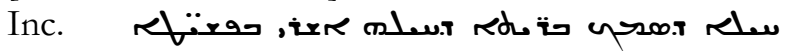


93. On the Blessed Martyrs

[A 66; Bk 82; Br 246]

Inc.



94. On All the Deceased III

[A 102; Bk 85; Br 258]

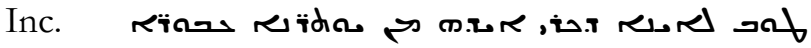

95. no title

[Bk 83; Br 259]

Inc.

96. no title

[Bk 84; Br 260]

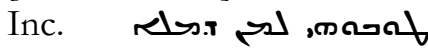

97. On Solitaries and Hermits

[Bk 164c; Br 261]

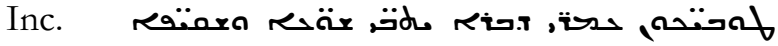

98. On the Saying of the Secular Poet, "Who ruined me and built me up?" [A 59; Be 674-691; Bk 86:II.108-140; Br 263]

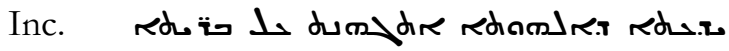

99. On the Love of Learning

[A 1; Be 1-12; Bk 87; Br 264]

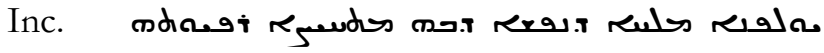

100. no title

[A 61; Bk 88; Br 265]

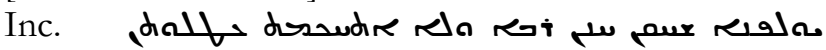

101. On the Crucifixion VI

[A 67 sex; Bk 175; Br 267]

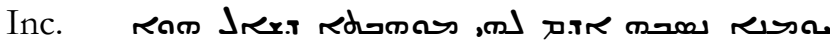

102. no title

[Bk 89; Br 270]

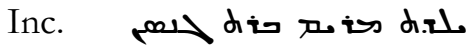


103. On the Verse, "Unless you turn and become like little children" I [A 88 prim; Bk 90; Br 271]

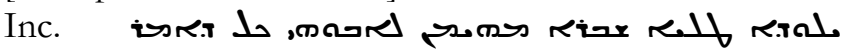

104. no title

[Bk 91; Br 277]

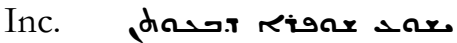

105. On the Samaritan Woman II

[A 79 sec; Bk 93; Br 281]

Inc.

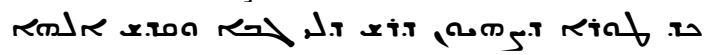

106. On the Magi who Came from the East

[A 78; Bk 94; Br 284]

Inc. هil.

107. On Tyranny and Oppression II

[A 63 sec; Bk 95; Br 285]

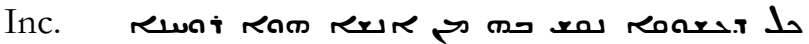

108. On the Deceased

[A 11; Be 45-49; Bk 96; Br 286]

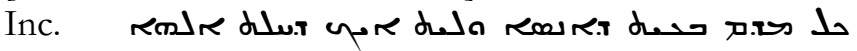

109. On the Verse "Unless you turn and become like little children" II

[A 88 sec; Bk 97; Br 287]

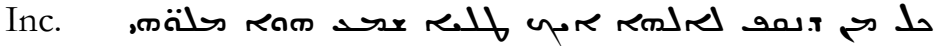

110. On the Man who did not consider his dignity but consorted with a beast and became like it

[Bk 98; Br 289]

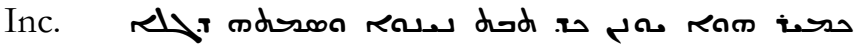

111. On All the Deceased I

[A 99; Bk 176; Br 291]

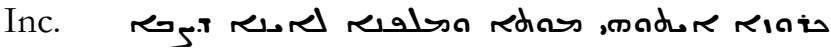

112. On Fasting and Almsgiving

[A 10; Be 359-381; Bk 101; Br 297$]$

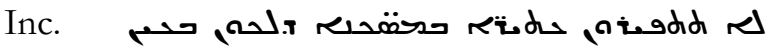


113. On the Enclosed Brethren I

[A 26 prim; Be 468-475; Bk 99; Br 298]

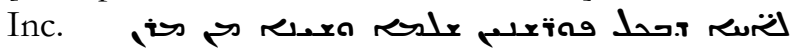

114. no title

[Bk 100; Br 300]



115. On the Rich of This World

[Bk 102; Br 303]

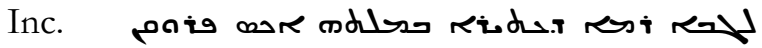

116. no title

[Bk 103]

Inc. له aم

117. On the Passibility and Impassibility of God the Word [A 24; Be 725-737; Bk 104; Br 305]

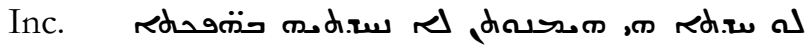

118. On the Samaritan Woman IV

[A 79 quart; Bk 105; Br 308]

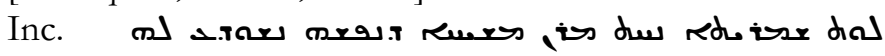

119. On Repentance

[A 54; Be 259-271; Bk 106; Br 309]

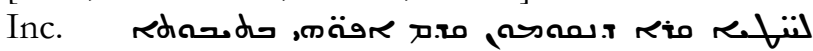

120. no title

Inc. dur Rit, K ont Rig

121. Ad Admonition

[Bk 107:II.68-74; Br 314]

Inc. rewes rigg rewar of

122. On the Apostates

[A 39; Be 612-621; Bk 108; Br 315]

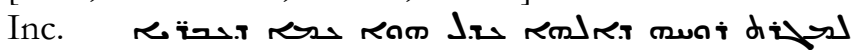


123. An Admonition

[Bk 72b; Br 316]

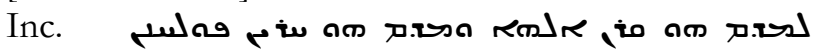

124. On the Time of the Pestilence

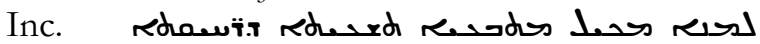

125. no title

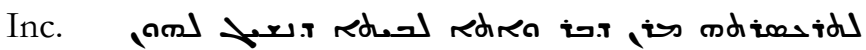

126. On the Sign that Appeared in the Sky

[A 9(8); Be 350-359; Bk 109; Br 324]

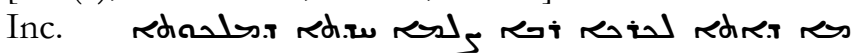

127. On [Deceased] Foreigners

[A 100; Bk 110; Br 326]

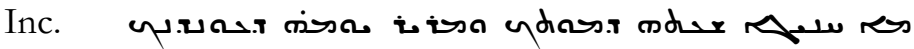

128. On [Deceased] Youths I

[Bk 177; Br 327; Zingerle"]

Inc.

129. On Perfection

[A 92; Bk 111; Br 329]

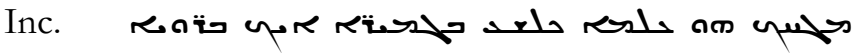

130. no title

[Bk 112; Br 331]

Inc. mads esto räras

131. On the Destruction of Beth Hur I

[A 37 prim; Be 587-598; Bk 113:I.206-224; Br 334]

Inc.

132. On the Coming of Our Lord

[A 77; Bk 114; Br 337]

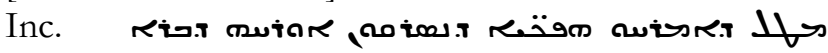

${ }_{9}$ P. Zingerle, Cbrestomathia Syriaca, 387-394. 
133. no title

[Bk 116; Br 339]

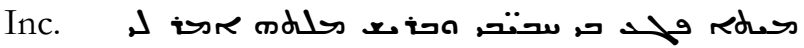

134. On the Crucifixion

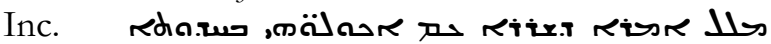

135. On the Faith

[A 94; Bk 117; Br 352]

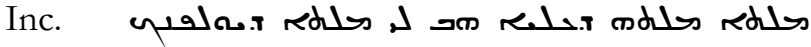

136. On the Falcon

[Bk 119; Br 355]

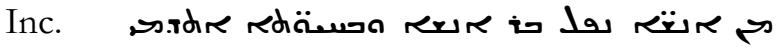

137. On the Enclosed Brethren VII

[A 26 sept; Be 520-531; Bk 120; Br 357]

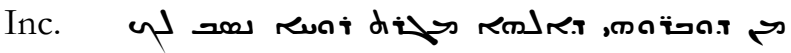

138. On Those who go to Soothsayers

[Be 830-837; Bk 121:II.220-236; Br 358]

Inc.

139. An Admonition

[A 43; Be 145-152; Bk 123; Br 359]

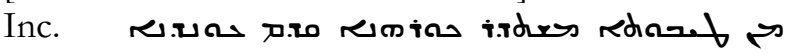

140. On the Enclosed Brethren IV

[A 26 quart; Be 492-502; Bk 124; Br 360]

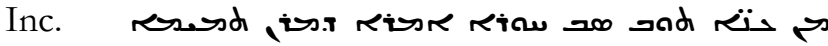

141. no title

[Bk 118; Br 363]

Inc. revads t.as res

142. On Supplication III

[A 55 ter; Be 664-668; Bk 122; Br 364]

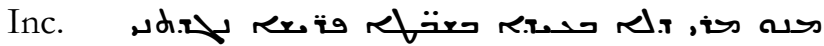


143. no title

[Bk 125; Br 368]

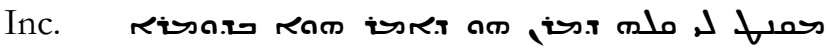

144. On Mary, the Holy Mother of God

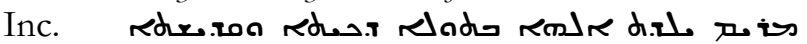

145. no title

[Bk 126; Br 381]

Inc. vקוs

146. On Poverty, which is True Freedom

[A 42; Be 135-144; Bk 127; Br 383]

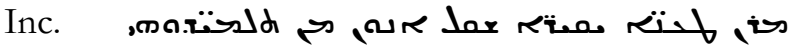

147. On Deceased Youths II

[A 96; Bk 128; Br 388]

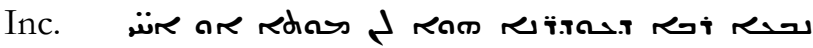

148. On [the saying], "With what power will Satan overcome a person in the trial?"

[A 25; Be 454-468; Bk 129:I.178-204; Br 397]

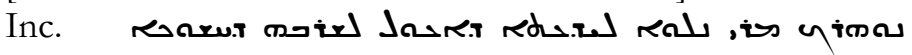

149. On the Fourth Vision of King Nebuchadnezzar

[Bk 131; Br 399]

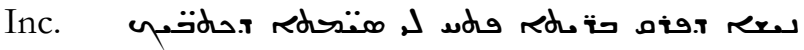

150. On the Incarnation

[Bk 184:I.50]

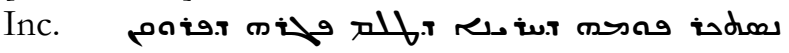

151. On the Perfection of the Brethren

[A 34; Be 539-566; Bk 164b:II.266-352; Br 407]

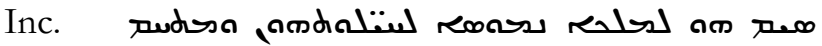

152. An Admonition

[Bk 133; Br 408]

Inc. مar mato 
153. On Supplication II

[A 55 sec; Be 284-295; Bk 134; Br 411]

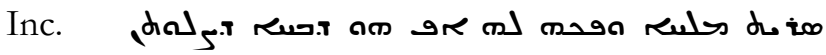

154. On the Destruction of Bet-Hur II

[A 37 sec; Be 598-612; Bk 135:I.226-248; Br 412]

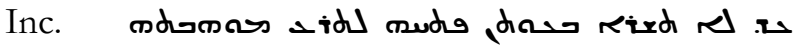

155. On the Cock

[Bk 136; Br 423]

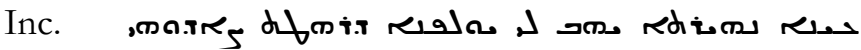

156. On the Natural Distinction of Natural Thoughts

[A 18; Be 399-408; Bk 137; Br 425]

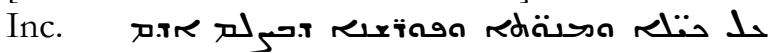

157. On the World and its Evils

[Bk 138; Br 431]

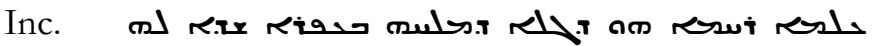

158. no title

[Bk 141; Br 433]

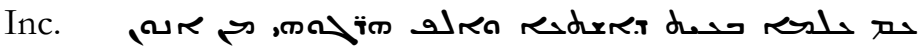

159. On the Samaritan Woman III

[A 79 ter; Bk 142; Br 434]

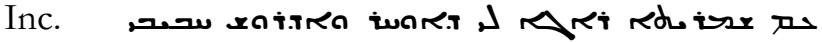

160. no title

[Bk 139; Br 437]

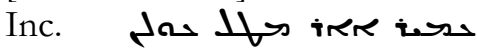

161. On the Blessed [Virgin Mary] and on Those who Pry

[Bk 140:I.78-84; Br 438]

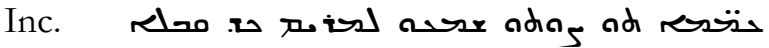

162. An Admonition

[A 6 sec; Be 25-36; Bk 144:II.142-162; Br 439]

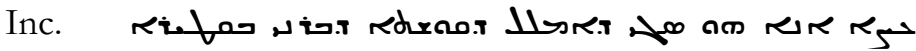


163. On Repentance

[A 52; Be 253-259; Bk 145; Br 442]

Inc.

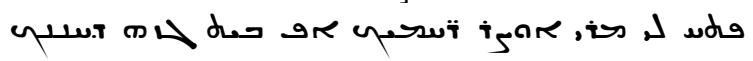

164. On the Enclosed Brethren $V$

[A 26 quint; Be 502-513; Bk 146; Br 449]

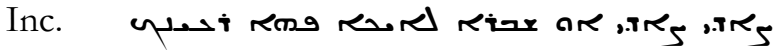

165. On the Saying of David, "I set the Lord before me at all times"

[Bk 147; Br 450]

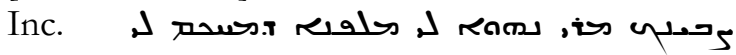

166. On the End Times

[Bk 148; Br 461]

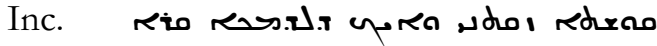

\section{On Creation}

[A 60; Be 691-711; Bk 149; Br 474]

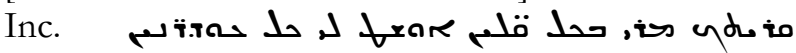

168. On the Holy Cross

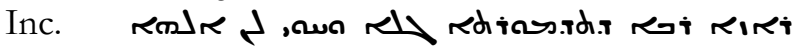

169. An Admonition

[A 14; Be 392-399; Bk 150; Br 477]

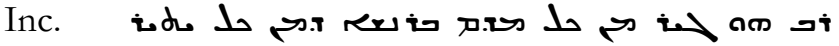

170. On the Resurrection

[Bk 151; Br 482]

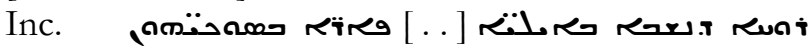

171. On the Enclosed Brethren II

[A 26 sec; Be 476-484; Bk 152; Br 483]

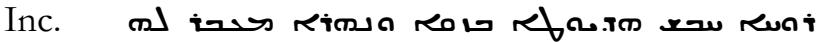

172. On the Lenten Fast II

[A 45 sec; Be 171-180; Bk 153:I.274-294; Br 498]

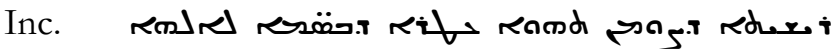


173. On Those who Accuse each other at Prayer and at the Liturgy [A 44; Be 153-158; Bk 156; Br 503]

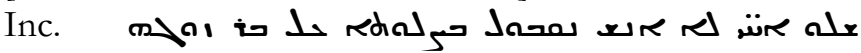

174. On the Crucifixion III

[A 67 ter; Bk 178; Br 505; Zingerle ${ }^{10}$ ]

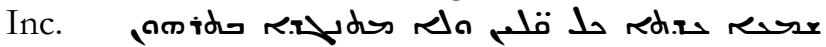

175. On the Deceased

[Bk 157; Br 506; Zingerle ${ }^{11}$; Assemani1 ${ }^{12}$ ]

Inc.

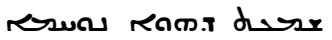

176. On the Samaritan Woman $V$

[A 79 quint; Bk 158; Br 507]

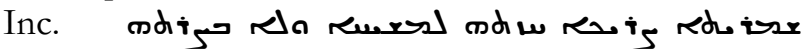

177. no title

[Bk 159]

Inc. Ja.

178. On Repentance

[A 40 sec; Be 127-134; Bk 160; Br 515]



179. On the verse, "Unless you turn and become like little children" III [A 88 ter; Bk 161; Br 519]

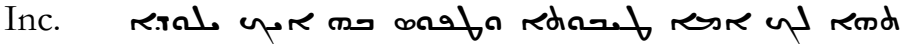

180. On Repentance

[A 40 prim; Be 621-641; Bk 164:II.236-266; Br 527]

Inc. ramd prex Rdard refi ar ald ad

181. On the Natural Composition of Humanity

[A 47; Be 239-253; Bk 162; Br 530]

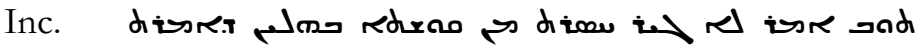

10 P. Zingerle, Chrestomathia Syriaca, 299-301.

11 P. Zingerle, Chrestomathia Syriaca, 313-335.

12 J.S. Assemani, Sancti Patris Nostri Ephraem Syri Opera Omnia quae exstant graece, syriace,latine, in sex tomos distributa (Rome 1732-1743) III.242247. 
182. On the Capital City

[Bk 163; Br 531; Moss $\left.{ }^{13}\right]$

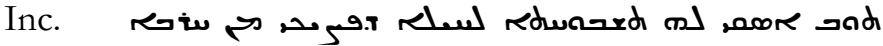

183. On "God does everything as a belp"

[A 58; Be 669-674; Bk 166; Br 536]

Inc.

184. On the Vessel for Boiling $W$ ater

[Bk 168; Br 537]

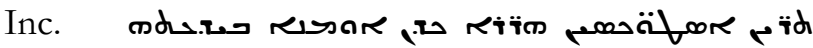

185. On the Feast of the Nativity

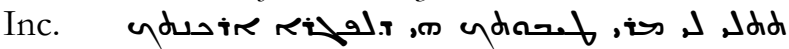

\section{MADRĀŠ̂̂E}

1. Against Those who Receive the Eucharist only after long Intervals [Bk 4:II.32-38]

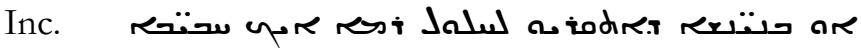

2. Against Those who Receive the Eucharist only after long Intervals [Bk 8:II.14-20]

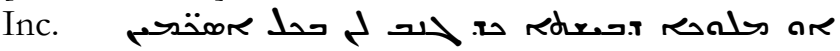

3. Against Those who Receive the Eucharist only after long Intervals [Bk 14:II.8-14]

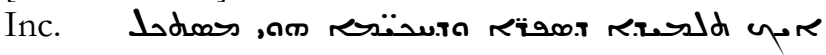

4. Against Those who Receive the Eucharist only after long Intervals [Bk 29:II.74-82]

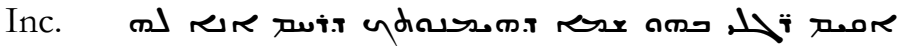

5. Against Those who Receive the Eucharist only after long Intervals [Bk 38:II.2-6]

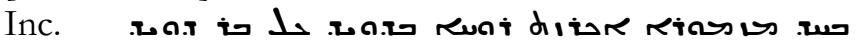

13 C. Moss, "Isaac of Antioch. Homily on the Royal City" (ZS 7 [1929]), 295-306, (8 [1932]), 61-72. 
6. On the Coming of the Lord

[Bk 53]

Inc.

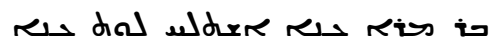

7. Against Those who Receive the Eucharist only after long Intervals [Bk 62:II.94-102]

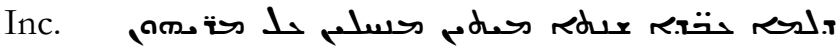

8. Against Those who Receive the Eucharist only after long Intervals [Bk 71:II.20-24]

Inc. riads 1 durex retiass redtrex R.taim

9. Against Those who Receive the Eucharist only after long Intervals

[Bk 76:II.104-108]

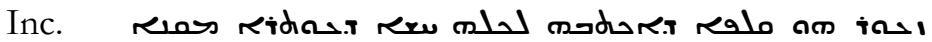

10. Against Those who Receive the Eucharist only after long Intervals [Bk 81:II.62-68]

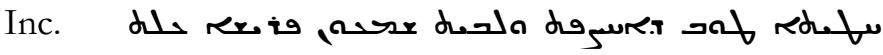

11. Against Those who Receive the Eucharist only after long Intervals [Bk 92:II.68-74]

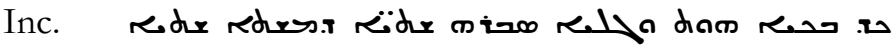

12. On the Coming of the Lord

[Bk 115]



13. Against Those who Receive the Eucharist only after long Intervals [Bk 130:II.90-94]

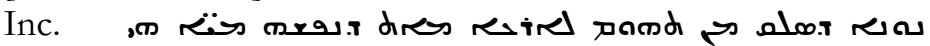

14. Against Those who Receive the Eucharist only after long Intervals [Bk 132:II.82-88]

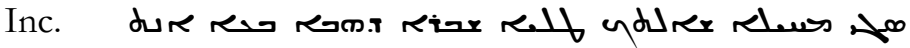

15. Against Those who Receive the Eucharist only after long Intervals [Bk 143:II.56-60]

Inc. 
16. Against Those who Receive the Eucharist only after long Intervals [Bk 154:II.38-44]

Inc.



17. Against Those who Receive the Eucharist only after long Intervals [Bk 155:II.46-56]

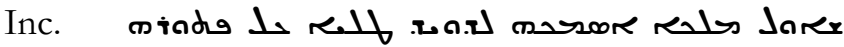

18. On the Coming of the Lord

[Bk 165]

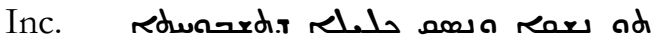

19. Against Those who Receive the Eucharist only after long Intervals

[Bk 167:II.26-32]

Inc. mit arda

\section{BIBLIOGRAPHY}

Assemani, J.S. Sancti Patris Nostri Ephraem Syri Opera Omnia quae exstant graece, syriace, latine, in sex tomos distributa. Rome, 1732-1743.

Brock, S.P. "The Published Verse Homilies of Isaac of Antioch, Jacob of Serugh, and Narsai: Index of Incipits.” JSS 32 (1987): 279-313.

Brock, S.P. "Syriac Studies in the Last Three Decades: Some Reflections." In VI Symposium Syriacum 1992, Orientalia Christiana Analecta 247, ed. R. Lavenant. Rome: Pontificio Istituto Orientale, 1994. Pp. 13-29.

Brock, S.P. "A Brief Guide to the Main Editions and Translations of the Works of St. Ephrem." The Harp 3 (1990): 7-29.

de Halleux, A. "Vingt ans d'étude critique des églises syriaques." In The Christian East: Its Institutions and its Thought. A Critical Reflection, Orientalia Christiana Analecta 251, ed. R.F. Taft. Rome: Pontificio Istituto Orientale, 1996. Pp. 145-179.

den Biesen, K. Bibliography of Ephrem the Syrian. Published by author, 2002.

Kazan, S. "Isaac of Antioch's Homily against the Jews." OrChr 45 (1961): 30-53.

Mathews, E.G., Jr. "A Bibliographical Clavis to the Corpus of Works attributed to Isaac of Antioch.” Hugoye 5.1 (2002).

Melki, J. "Saint Ephrem le Syrien, un bilan de l'édition critique." ParOr 11 (1983): 3-88.

Moss, C. "Isaac of Antioch. Homily on the Royal City." ZS 7 (1929): 295306; 8 (1932): 61-72.

Zingerle, P. Chrestomathia Syriaca. Rome, 1871. 